\title{
Patient-reported outcomes in those consuming medical cannabis: a prospective longitudinal observational study in chronic pain patients
}

\section{Résultats rapportés par les patients consommant du cannabis médical : une étude observationnelle longitudinale prospective chez des patients souffrant de douleur chronique}

\author{
Howard Meng, MD • M. Gabrielle Page, PhD • Prabjit Ajrawat • Amol Deshpande, MD, \\ MBA · Bana Samman • Mary Dominicis · Karim S. Ladha, MD · Joseph Fiorellino, MD • \\ Alexander Huang, MD • Yuvaraj Kotteeswaran, MD · Alex McClaren-Blades, MD • \\ Lakshmi P. Kotra, PhD • Hance Clarke, MD, PhD, FRCPC
}

Received: 8 May 2020/Revised: 3 October 2020/Accepted: 9 October 2020/Published online: 20 January 2021

(C) Canadian Anesthesiologists' Society 2021

\begin{abstract}
Purpose We investigated patients with chronic pain seeking medical cannabis. We assessed their demographics, patterns of cannabis use, and the longterm effectiveness of cannabis on their pain and functional domains.

Methods This observational study enrolled patients between 8 September 2015 and 31 July 2018 from
\end{abstract}

Supplementary Information The online version contains supplementary material available at https://doi.org/10.1007/s12630020-01903-1.

H. Meng, MD

Department of Anesthesiology and Pain Medicine, University of

Toronto, Toronto, ON, Canada

\section{G. Page, $\mathrm{PhD}$}

Centre de recherche du Centre hospitalier de l'Université de Montréal (CRCHUM), Département d'anesthésiology et médecine de la douleur, Faculté de médecine, Université de Montréal, Montreal, QC, Canada

P. Ajrawat · B. Samman · M. Dominicis

Department of Anesthesia, Toronto General Hospital, Toronto,

ON, Canada

\author{
A. Deshpande, MD, MBA \\ Toronto Rehabilitation Institute, Toronto, ON, Canada
}

\section{K. S. Ladha, MD}

Department of Anesthesia, St. Michael's Hospital, Toronto, ON M5B 1W8, Canada

Centre For Cannabinoid Therapeutics, Toronto, ON, Canada community-based cannabis clinics in Ontario, Canada. In addition to collecting demographic information, the primary outcomes studied were pain intensity and painrelated interference scores assessed at baseline, three, six, and 12 months. Using validated questionnaires, we also assessed anxiety, depression, quality of life (QoL), general health symptoms, neuropathic pain, self-reported opioid consumption, and adverse events.

Results Of the 1,000 patients consented, 757 (76\%) participated at one or more of the study time points. At six and 12 months, $230(30.4 \%)$ and $104(13.7 \%)$ of participants

J. Fiorellino, MD

Department of Anesthesiology and Pain Medicine, University of Toronto, Toronto, ON, Canada

Department of Anesthesia, Toronto General Hospital, Toronto, ON, Canada

Centre For Cannabinoid Therapeutics, Toronto, ON, Canada

Transitional Pain Service, Toronto General Hospital, Toronto, ON, Canada

A. Huang, MD - A. McClaren-Blades, MD

Department of Anesthesiology and Pain Medicine, University of Toronto, Toronto, ON, Canada

Department of Anesthesia, Toronto General Hospital, Toronto, ON, Canada

Transitional Pain Service, Toronto General Hospital, Toronto, ON, Canada 
were followed up, respectively. Most participants were female (62\%), Caucasian (91\%), and sought cannabis for pain relief (88\%). Time was a significant factor associated with improvement in pain intensity $(P<0.001)$, pain-related interference scores $(P<0.001)$, QoL $(P<0.001)$, and general health symptoms $(P<0.001)$. Female sex was significantly associated with worse outcomes than male sex including pain intensity $(P<0.001)$ and pain-related interference $(P<0.001)$. The proportion of individuals who reported using opioids decreased by half, from $40.8 \%$ at baseline to $23.9 \%$ at 12 months.

Conclusion Despite significant challenges to collecting long-term observational data on patients who attempted a trial of cannabis products, approximately one-third of patients in the cohort remained on medical cannabis for six months. In this cohort, pain intensity and pain-related interference scores were reduced and QoL and general health symptoms scores were improved compared with baseline.

\section{Résumé}

Objectif Nous avons étudié des patients souffrant de douleur chronique et cherchant à obtenir du cannabis médical. Nous avons évalué leurs données démographiques, leurs habitudes de consommation de cannabis et l'efficacité à long terme du cannabis sur leur douleur et leurs domaines fonctionnels.

Méthode Cette étude observationnelle a recruté des patients entre le 8 septembre 2015 et le 31 juillet 2018 dans des cliniques communautaires de cannabis en Ontario, au Canada. En plus de recueillir des renseignements démographiques, les critères d'évaluation principaux étudiés étaient l'intensité de la douleur et les scores d'interférence liés à la douleur évalués au début de l'étude et à trois, six et 12 mois. À l'aide de questionnaires validés, nous avons également évalué l'anxiété, la dépression, la

Y. Kotteeswaran, MD

Department of Anesthesia, Northern Ontario School of

Medicine, Thunder Bay, ON, Canada

L. P. Kotra, PhD

Centre For Cannabinoid Therapeutics, Toronto, ON, Canada

Department of Pharmaceutical Sciences, Leslie Dan Faculty of Pharmacy, University of Toronto, Toronto, ON, Canada

Krembil Research Institute, University Health Network, Toronto, ON, Canada

H. Clarke, MD, PhD, FRCPC ( $\square)$

Department of Anesthesiology and Pain Medicine, University of Toronto, Toronto, ON, Canada

e-mail: hance.clarke@uhn.ca

Department of Anesthesia, Toronto General Hospital, Toronto, ON, Canada qualité de vie (QdV), les symptômes généraux de santé, la douleur neuropathique, la consommation d'opioüdes rapportée et les effets indésirables.

Résultats Sur les 1000 patients consentants, 757 (76\%) ont participé à un ou plusieurs des points d'analyse de l'étude. A' six et douze mois, 230 (30,4\%) et 104 (13,7\%) patients ont participé, respectivement. La plupart des participants étaient des femmes (62 \%) d'origine caucasienne (91\%) et cherchaient à soulager leur douleur avec du cannabis (88\%). Le temps était un facteur important associé à l'amélioration de l'intensité de la douleur $(P<0,001)$, aux scores d'interférence liés à la douleur $(P<0,001)$, à la $Q d V(P<0,001)$, et aux symptômes de santé généraux $(P<0,001)$. Le sexe féminin a été significativement associé à des pronostics moins bons que le sexe masculin, y compris en matière d'intensité de la douleur $(P<0,001)$ et d'interférences liées à la douleur $(P$ $<0,001)$. La proportion de personnes qui ont déclaré utiliser des opioïles a diminué de moitié, passant de 40,8 $\%$ au début de l'étude à 23,9\% à 12 mois.

Conclusion Malgré des défis importants dans la collecte de données observationnelles à long terme concernant les patients qui participent à une étude sur les produits $d u$ cannabis, environ un tiers des patients de la cohorte ont continué à prendre du cannabis médical pendant six mois. Dans cette cohorte, l'intensité de la douleur et les scores d'interférence liés à la douleur ont été réduits, et les scores de $Q d V$ et de symptômes généraux de santé se sont améliorés par rapport au début de la période à l'étude.

One in five Canadian adults suffers from chronic pain, amounting to estimated annual related costs to the

Centre For Cannabinoid Therapeutics, Toronto, ON, Canada

Transitional Pain Service, Toronto General Hospital, Toronto, ON, Canada

Krembil Research Institute, University Health Network, Toronto, ON, Canada

Pain Research Unit, Department of Anesthesia and Pain Management, GoodHope Ehlers Danlos Clinic, Toronto General Hospital, Toronto, ON M5G 2C4, Canada

University of Toronto Centre for the Study of Pain, University of Toronto, Toronto, ON, Canada 
Canadian economy of \$50-60 billion. ${ }^{1}$ Nevertheless, since the likelihood of experiencing chronic pain increases with age, the prevalence as well as the social and economic burden of chronic pain are expected to rise substantially as the Canadian population ages. ${ }^{2}$ Chronic pain is often associated with reduced quality of life, diminished mental health, and increased long-term disability. ${ }^{2-4}$ Historically, opioids have been prescribed for treating chronic pain and their use has increased four-fold in North America from 1997 to 2007, followed by years of stabilization between 2010 and 2017. ${ }^{5,6}$ Opioid use is associated with serious adverse events and has limited improvements in functionality and mood, and long-term opioid utilization increases the probability of opioid diversion, abuse, and addiction. ${ }^{7,8}$ Given the North American opioid crisis and the publication of the Canadian opioid guideline for chronic non-cancer pain (CNCP), ${ }^{9}$ utilizing effective alternatives to opioids for the treatment of both $\mathrm{CNCP}$ and cancer pain has become a priority. ${ }^{9,10}$

The routine use of cannabis for a medical condition has been reported in $10-15 \%$ of patients with the majority consuming it as an adjunct to help manage their chronic pain symptoms. ${ }^{11-13}$ Different cannabis chemotypes are composed of distinct concentrations of delta-9tetrahydrocannabinol (THC) and cannabidiol (CBD) that are typically consumed through smoking, inhaling/vaping, or by oral ingestion. Tetrahydrocannabinol is known to induce a psychotropic effect whereas CBD may have more of an analgesic and anti-inflammatory role. ${ }^{14,15}$ Recent systematic reviews and meta-analyses have found conflicting results of cannabis-based products for treatment of chronic pain. ${ }^{16-18}$ In addition to its disputed analgesic effects, studies have also shown conflicting results with regards to cannabis use and sleep quality, anxiety, opioid consumption, and its potential as an opioidsparing agent. ${ }^{12,19-23}$

Cannabis has been touted as a solution to the opioid crisis as it has shown opioid-sparing effects in preclinical and clinical studies. ${ }^{24}$ Nevertheless, further research is needed to identify the optimal make-up, ratio, and dosage of cannabinoids to minimize harms and maximize benefits. Critical methodological problems exist with the clinical studies to date, with the most salient being the short followup windows (hours or days) that limit conclusions. Given the paucity of large-scale, longitudinal clinical studies investigating the effects of cannabis products in patients, we undertook a prospective observational study of patients enrolled in Ontario, Canada community cannabis clinics. The aim of the study was to assess the impact of cannabis on pain intensity and pain-related interference for patients consuming cannabis for up to 12 months. Secondary aims were to identify associated changes in opioid consumption, mental health, quality of life, and general health symptoms.

\section{Methods}

This was a prospective observational cohort study that enrolled patients between 28 September 2015 and 31 July 2018. Ethics review board approval was obtained on 9 September 2015 from Veritas IRB Inc. (Saint-Laurent, QC, Canada) (IRB\#15040-13:32:119-09-2015). An a priori sample of 1,000 adult patients with chronic diseases that received their medical cannabis document at Ontario Canvas Rx Cannabis Clinics (Toronto, Canada) were enrolled. These clinics operated as for-profit entities; however, the Ontario Health Insurance Plan, a government funded healthcare plan, covered the cost of patient assessments. Patients first saw the physician, and having received their medical cannabis authorization document, were subsequently recruited for this study by cannabis counsellors. The recruitment process involved discussion with patients of the risks, benefits, and logistics of the study, and written informed consent was obtained. Patients did not receive compensation for participation in this study and enrollment into the study did not affect their care at the clinic.

We collected demographic information and baseline questionnaires on each patient's initial visit. We did not collect detailed information regarding prior cannabis use, such as the indication for use, form of cannabis consumed, THC/CBD content, nor about reimbursement for cannabis products used. The patients completed questionnaires at their initial visit, and at three, six, and 12 months. These questionnaires were to assess pain severity (average pain over the last week on a numerical rating scale); average score on pain interference (from the Brief Pain Inventory $)^{25}$; anxiety and depression subscores based on an average of the two questions (Personal Health Questionnaire [PHQ4] $)^{26}$; general quality of life based on the last question, out of 100 (EuroQol 5 Dimensions/3 Level Questionnaire [EQ-5D-3L]) ${ }^{27}$; Edmonton Symptom Assessment System (ESAS) based on the average score across all items ${ }^{28}$; Self-administered Leeds Assessment of Neuropathic Symptoms and Signs (S-LANSS) ${ }^{29}$; opioid consumption (not form or dosage); and symptoms and adverse events. We provided each patient with a personal unique identifier to access a secure online survey hosted by Survey Monkey (San Mateo, California, USA).

\section{Statistical analysis}

Descriptive statistical methods were used to summarize characteristics of individuals seeking medical cannabis and patterns of cannabis use over time, including mean (standard deviations [SD]) and frequencies. Linear mixed effect models were used to examine the effectiveness of cannabis use on core outcomes. At each time-point, data from individuals who reported they did not use cannabis 
since the previous time-point were excluded. Non-normally distributed variables (Shapiro-Wilks and KolmogorovSmirnov tests $P<0.05$, Fischer skewness coefficient and Fischer coefficient of kurtosis more than \pm 1.96 ) were addressed by selecting appropriate transformation. Separate models were run for the following core outcomes: average pain intensity, pain interference, anxiety, depression, quality of life, and general health symptoms. For each model, a first-order auto-regressive covariance type was specified and fixed-effects included baseline cannabis use status (cannabis naïve vs user), reason for seeking medical cannabis (pain $v s$ other; except for pain intensity and pain-related interference that were answered only by those seeking medical cannabis for pain), time, and their interactions. Interaction terms were removed if non-significant $(P \geq 0.01)$. Alpha was set at 0.01 to account for potential type-I errors associated with testing multiple models. Given the high proportion of missing data at 12 months, sensitivity analysis was conducted by re-running the above-mentioned model by excluding the last follow-up time-point (12-month) and comparing the models.

\section{Results}

Characteristics of individuals seeking medical cannabis

A total of 1,000 patients consented to the study and 757 participants completed baseline questionnaires and provided demographic information (Figure). Of the remaining 243 participants that provided consent for enrollment, 215 participants completed the baseline questionnaire but did not complete any of the follow-up questionnaires and 28 participants consented but did not complete either baseline or follow-up questionnaires. As shown in Table 1 , the majority of patients $(n=466 ; 61.6 \%)$ were female, predominantly Caucasian $(n=688 ; 90.8 \%)$, and all age groups were well represented; the $\geq 65 \mathrm{yr}$ age group was the smallest $(n=102 ; 13.5 \%)$ and the $45-54 \mathrm{yr}$ age group was the largest $(n=199 ; 26.3 \%)$. Approximately half $(n=384 ; 50.8 \%)$ had at least some college education and one-third $(n=263 ; 34.7 \%)$ were employed full-time. More than one-third ( $n=297 ; 39.2 \%)$ of participants were already using cannabis at baseline. The vast majority sought cannabis for pain relief $(n=673 ; 88.9 \%)$. Other reasons for seeking medical cannabis were diverse and included common conditions such as anxiety $(n=20$; $2.6 \%)$ and insomnia $(n=11 ; 1.5 \%)$. There were no significant differences in sex among individuals seeking cannabis for pain $(P=0.42)$. There were significantly more men $(n=345 ; 45.6 \%)$ using cannabis at baseline than women $(n=268 ; 35.4 \%)(P=0.047)$; however, our

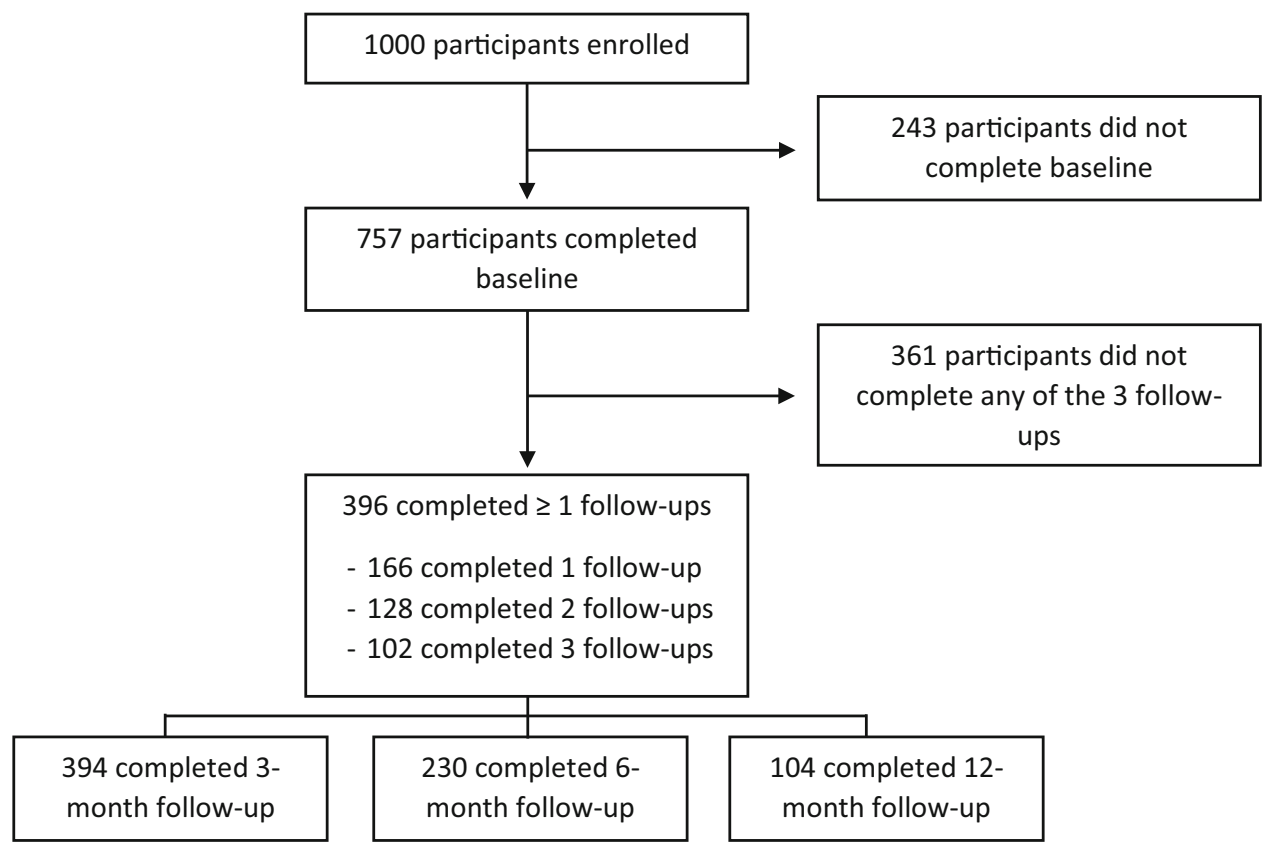

Figure Patient response flow chart 
Table 1 Demographic, pain type and psychosocial characteristics of participants seeking medical cannabis and for those who completed at least one follow-up

\begin{tabular}{|c|c|c|c|c|}
\hline & \multirow[t]{2}{*}{ Total sample $(n=757)$} & \multicolumn{3}{|c|}{ Sample included in the longitudinal analyses } \\
\hline & & Cannabis naïve $(n=241)$ & Cannabis users $(n=155)$ & Total $(n=396)$ \\
\hline \multicolumn{5}{|l|}{ Gender, $n(\%)$} \\
\hline Female & $466(61.6)$ & $160(66.4)$ & $88(56.8)$ & $248(62.6)$ \\
\hline Male & $290(38.3)$ & $80(33.2)$ & $67(43.2)$ & $147(37.1)$ \\
\hline Transgender & $1(0.1)$ & $1(0.4)$ & $0(0.0)$ & $1(0.3)$ \\
\hline \multicolumn{5}{|l|}{ Age, yr, $n(\%)$} \\
\hline $25-34$ & $106(14.0)$ & $22(9.1)$ & $30(19.4)$ & $52(13.1)$ \\
\hline $35-44$ & $175(23.1)$ & $52(21.6)$ & $44(28.4)$ & $96(24.2)$ \\
\hline $45-54$ & $199(26.3)$ & $59(24.5)$ & $37(23.9)$ & $96(24.2)$ \\
\hline $55-64$ & $174(23.0)$ & $64(26.6)$ & $33(21.3)$ & $97(24.5)$ \\
\hline $65+$ & $102(13.5)$ & $44(18.3)$ & $11(7.1)$ & $55(13.9)$ \\
\hline Prefers not to answer & $1(0.1)$ & $0(0.0)$ & $0(0.0)$ & $0(0.0)$ \\
\hline \multicolumn{5}{|l|}{ Ethnicity $n(\%)$} \\
\hline White/Caucasian & $688(90.9)$ & $219(90.9)$ & $140(90.3)$ & $359(90.7)$ \\
\hline Other & $69(9.1)$ & $22(9.1)$ & $15(9.7)$ & $37(9.3)$ \\
\hline \multicolumn{5}{|l|}{ Education $n(\%)$} \\
\hline Less than grade 12 & $59(7.8)$ & $9(3.7)$ & $10(6.5)$ & $19(4.8)$ \\
\hline Graduated high school & $135(17.8)$ & $42(17.4)$ & $25(16.1)$ & $67(16.9)$ \\
\hline Associate or technical degree & 179 (23.6) & $50(20.7)$ & $53(34.2)$ & $103(26.0)$ \\
\hline Some college, no degree & $195(25.8)$ & $59(24.5)$ & $31(20.0)$ & $90(22.7)$ \\
\hline Bachelor's degree & $131(17.3)$ & $52(21.6)$ & $27(17.4)$ & 79 (19.9) \\
\hline Master's degree or higher & $58(7.7)$ & $29(12.0)$ & $9(5.8)$ & $38(9.6)$ \\
\hline \multicolumn{5}{|l|}{ Employment $n(\%)$} \\
\hline Full-time & $263(34.7)$ & $72(29.9)$ & $60(38.7)$ & $132(33.3)$ \\
\hline Part-time & $55(7.3)$ & $18(7.5)$ & $11(7.1)$ & $29(7.3)$ \\
\hline Unemployed or unable to work & $175(23.1)$ & $39(16.2)$ & $36(23.2)$ & $75(18.9)$ \\
\hline Retired & $123(16.2)$ & $59(24.5)$ & $15(9.7)$ & $74(18.7)$ \\
\hline Self-employed & $74(9.8)$ & $25(10.4)$ & $19(12.3)$ & $44(11.1)$ \\
\hline Other & $67(8.9)$ & $28(11.6)$ & $14(9.0)$ & $42(10.6)$ \\
\hline \multicolumn{5}{|l|}{ Seeking cannabis for pain $n(\%)$} \\
\hline Yes & $673(88.9)$ & $199(82.6)$ & $155(100.0)$ & $354(89.4)$ \\
\hline No & $84(11.1)$ & $42(17.4)$ & $0(0.0)$ & $42(10.6)$ \\
\hline \multicolumn{5}{|l|}{ Neuropathic pain $n(\%)^{*}$} \\
\hline Yes & $213(28.1)$ & $63(26.1)$ & $56(36.1)$ & 119 (33.6) \\
\hline No & $460(60.8)$ & $136(56.4)$ & $99(63.9)$ & $235(66.4)$ \\
\hline
\end{tabular}

*Neuropathic Pain questionnaire answered only by those reporting seeking cannabis for pain relief.

analyses showed that there was no difference in outcomes between baseline cannabis users and cannabis naïve users. There were also no significant sex differences in terms of daily grams used $(P=0.35)$.

There were no significant differences in sex, age, ethnicity, indication for cannabis use (pain), or baseline cannabis user status in participants who completed at least one follow-up $(n=396)$ vs those who did not $(n=361)$. Nevertheless, those who did not complete any follow-up were more likely to be unemployed or unable to work $(P=$
$0.01)$, more likely to have $<$ grade 12 education $(P<$ $0.001)$, and reported higher mean levels of depressive symptoms ( 2.3 vs $2.0 ; P=0.02)$, anxiety ( 2.4 vs $1.8 ; P<$ 0.001 ), common symptoms (ESAS, $3.6 v s 3.2 ; P=0.002$ ), and lower mean levels of quality of life (54.8 vs 58.6; $P=$ 0.01 ) compared with those who completed one or more follow-ups.

The number of participants who completed three, six, and 12-month follow-ups were 394 (52.0\%), 230 (30.4\%), and $104(13.7 \%)$ respectively. There were no significant 


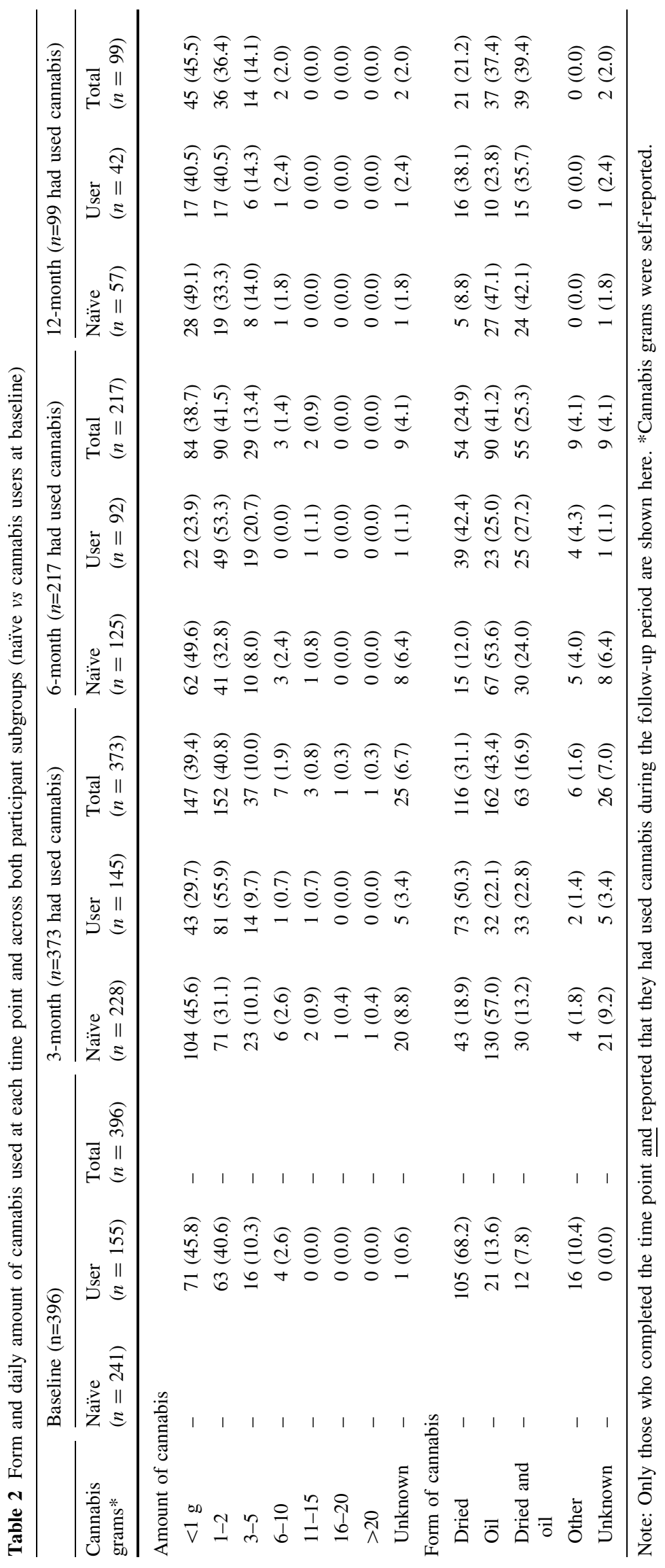


Table 3 Opioid consumption status over time among those reporting baseline pain and included in the longitudinal analyses.

\begin{tabular}{|c|c|c|c|}
\hline & \multicolumn{3}{|c|}{ Participant seeking cannabis for pain and who are included in the longitudinal analyses } \\
\hline & Cannabis naïve $(n=199)$ & Cannabis users $(n=155)$ & Total $(n=354)$ \\
\hline \multicolumn{4}{|c|}{ Opioid consumption status at baseline, $n(\%)$} \\
\hline Yes & $82(42.49)$ & $60(38.71)$ & $142(40.80)$ \\
\hline No & $111(57.51)$ & $95(61.29)$ & $206(59.20)$ \\
\hline Missing data & 6 & 0 & 6 \\
\hline \multicolumn{4}{|c|}{ Opioid consumption status at 3 months, $n(\%)$} \\
\hline Yes & $55(30.56)$ & $36(26.09)$ & $91(28.62)$ \\
\hline No & $125(69.44)$ & $102(73.91)$ & $227(71.38)$ \\
\hline Missing data & 19 & 17 & 36 \\
\hline \multicolumn{4}{|c|}{ Opioid consumption status at 6 months, $n(\%)$} \\
\hline Yes & $27(26.47)$ & $18(20.00)$ & $45(23.44)$ \\
\hline No & $75(73.53)$ & $72(80.00)$ & $147(76.56)$ \\
\hline Missing data & 97 & 65 & 162 \\
\hline \multicolumn{4}{|c|}{ Opioid consumption status at 12 months, $n(\%)$} \\
\hline Yes & $14(29.79)$ & $7(17.07)$ & $21(23.86)$ \\
\hline No & $33(70.21)$ & $34(82.93)$ & $67(76.14)$ \\
\hline Missing data & 152 & 114 & 266 \\
\hline
\end{tabular}

*Missing data were not included in the calculation of the percentages of individuals reporting having stopped opioids.

differences in age, ethnicity, work status, education level, indication for cannabis use (pain), or baseline cannabis user status between those who completed all three follow-ups $(n=102)$ and those who did not $(n=655)$. Nevertheless, those who completed all three follow-ups were more likely to be male $(P=0.001)$ and reported lower mean levels of anxiety $(1.6$ vs $2.1 ; P=0.01)$.

Patterns of cannabis consumption over time

Few individuals who completed follow-ups reported that they did not use cannabis (21/394 at three months, 13/230 at six months, and 5/104 at 12 months). Common reasons for not using cannabis included financial reasons and difficulty accessing supplies.

The dosage of cannabis and number of daily grams consumed over time based on baseline cannabis status (users vs naïve) are shown in Table 2 . While nearly a quarter of existing cannabis users consumed oil formulations at three months $(n=32 ; 22.1 \%)$ and at 12 months $(n=10 ; 23.8 \%)$, about one-half of cannabis naïve individuals did at three months $(\mathrm{n}=130 ; 57.0 \%)$ and at 12 months $(n=27 ; 47.1 \%)$. Fewer individuals used only dried cannabis over time ( $n=116,31.1 \%$ at three months; $n=$ $21 ; 21.2 \%$ at 12 months) and more individuals reported using a combination of dried cannabis and oil-based cannabis over time $(n=63 ; 16.9 \%$ at three months; $n=$ $39.4 ; 39.4 \%$ at 12 months). At the 12-month time-point, 21 of the 104 the patients reported that they exclusively consumed dried cannabis. There was an overall gravitation towards oil-based products, not only for the overall sample, but also in both cannabis naïve and cannabis users at baseline (Table 2).

\section{Patterns of opioid consumption}

Patterns of opioid consumption as a function of cannabis consumption was also examined. Among all participants who reported seeking cannabis for pain $(n=673), 283$ (42.1\%) reported being on opioid therapy at baseline. Among those who completed at least one follow-up, 142 $(40.8 \%)$ were on opioid therapy at baseline and this proportion dropped to $23.9 \%$ at 12 months (Table 3). When only considering individuals who were on opioid therapy at baseline, 83 of 125 (66.4\%) who completed the threemonth follow-up were still on opioids. This proportion decreased to $53.5 \%(n=38 / 71)$ at six months and to $50.0 \%$ $(n=19 / 38)$ at 12 months.

Effectiveness of cannabis consumption

As shown in Table 4, scores on pain intensity, pain-related interference, quality of life, and general health symptoms significantly improved over time. Baseline cannabis status was not significantly associated with any of the outcomes (all $P>0.01$ ). Seeking cannabis for pain was associated 
Table 4 Validated questionnaires for functional outcomes of participants seeking medical cannabis and for those who completed at least one follow-up

\begin{tabular}{|c|c|c|c|c|}
\hline & \multirow{2}{*}{ Total sample $n=757$ ) } & \multicolumn{3}{|c|}{ Sample included in the longitudinal analyses } \\
\hline & & Cannabis naïve $(n=241)$ & Cannabis users $(n=155)$ & Total $(n=396)$ \\
\hline \multicolumn{5}{|c|}{ Pain interference (BPI), mean (SD)* } \\
\hline Baseline & $6.29(2.0)$ & $6.23(1.8)$ & $6.26(2.2)$ & $6.24(2.0)$ \\
\hline 3-month follow-up & - & $4.91(2.5)$ & $5.40(2.3)$ & $5.11(2.4)$ \\
\hline 6-month follow-up & - & $4.45(2.6)$ & $5.12(2.5)$ & $4.75(2.6)$ \\
\hline 12-month follow-up & - & $4.73(2.6)$ & $4.51(2.8)$ & $4.63(2.7)$ \\
\hline \multicolumn{5}{|c|}{ Average pain intensity-NRS11, mean (SD)* } \\
\hline Baseline & $5.89(1.6)$ & $5.93(1.6)$ & $5.75(1.8)$ & $5.85(1.7)$ \\
\hline 3-month follow-up & - & $4.83(1.8)$ & $5.21(1.8)$ & $4.99(1.8)$ \\
\hline 6-month follow-up & - & $4.77(1.8)$ & $4.79(1.8)$ & $4.78(1.8)$ \\
\hline 12-month follow-up & - & 4.79 (1.6) & $4.71(2.1)$ & $4.76(1.8)$ \\
\hline \multicolumn{5}{|c|}{ Worst Pain Intensity-NRS11, mean (SD)* } \\
\hline Baseline & $7.89(1.5)$ & $7.92(1.5)$ & $7.88(1.5)$ & $7.91(1.5)$ \\
\hline 3-month follow-up & - & $6.81(1.9)$ & $7.05(2.0)$ & $6.91(2.0)$ \\
\hline 6-month follow-up & - & $6.43(2.3)$ & $6.94(2.1)$ & $6.66(2.2)$ \\
\hline 12-month follow-up & - & $6.92(2.0)$ & $6.41(2.3)$ & $6.69(2.1)$ \\
\hline \multicolumn{5}{|c|}{ Anxiety (PHQ4-anxiety subscore), mean (SD) } \\
\hline Baseline & $2.05(1.9)$ & $1.72(1.9)$ & $1.83(1.8)$ & $1.76(1.9)$ \\
\hline 3-month follow-up & - & $2.63(2.7)$ & $2.81(2.5)$ & $2.70(2.6)$ \\
\hline 6-month follow-up & - & $2.10(2.0)$ & $2.22(2.0)$ & $2.15(2.0)$ \\
\hline 12-month follow-up & - & $1.39(1.6)$ & $1.22(1.3)$ & $1.32(1.5)$ \\
\hline \multicolumn{5}{|c|}{ Depression (PHQ4-depression subscore), mean (SD) } \\
\hline Baseline & $2.11(1.8)$ & $1.96(1.8)$ & $1.97(1.7)$ & $1.96(1.7)$ \\
\hline 3-month follow-up & - & $1.91(2.1)$ & $1.86(2.0)$ & $1.89(2.0)$ \\
\hline 6-month follow-up & - & $1.21(1.6)$ & $1.46(1.7)$ & $1.31(1.6)$ \\
\hline 12-month follow-up & - & $1.95(2.1)$ & $1.22(1.3)$ & $1.90(2.1)$ \\
\hline \multicolumn{5}{|l|}{ ESAS, mean (SD) } \\
\hline Baseline & $3.36(1.7)$ & $3.17(1.7)$ & $3.20(1.6)$ & $3.18(1.6)$ \\
\hline 3-month follow-up & - & $2.48(1.5)$ & $2.66(1.5)$ & $2.55(1.5)$ \\
\hline 6-month follow-up & - & $2.42(1.4)$ & $2.84(1.7)$ & $2.60(1.5)$ \\
\hline 12-month follow-up & - & $2.41(1.5)$ & $2.44(1.7)$ & $2.42(1.6)$ \\
\hline \multicolumn{5}{|c|}{ Quality of life (EQ-5D-global score) mean (SD) } \\
\hline Baseline & $56.79(20.3)$ & $58.55(20.2)$ & $58.61(19.8)$ & $58.57(20.0)$ \\
\hline 3-month follow-up & - & $64.90(20.3)$ & $64.28(20.2)$ & $64.65(20.2)$ \\
\hline 6-month follow-up & - & $67.52(18.5)$ & $65.23(20.9)$ & $66.54(20.0)$ \\
\hline 12-month follow-up & - & $67.91(20.6)$ & $68.30(22.1)$ & $68.07(21.1)$ \\
\hline
\end{tabular}

*Questionnaire answered only by those reporting seeking cannabis for pain relief.

EQ-5D = EuroQol 5 Dimensions Questionnaire; ESAS = Edmonton Symptom Assessment System; NRS = numerical rating scale; PHQ4 = Personal Health Questionnaire; SD = standard deviation.

with worse mean general health symptoms based on the EQ-5D-3L compared with those seeking medical cannabis for other reasons (2.9 vs 2.1, respectively; $P=0.004)$; this variable was not significantly associated with any of the other measured outcomes. Neuropathic pain status was significantly associated with average pain intensity and pain interference; individuals with neuropathic pain had significantly higher overall mean levels of average pain (5.6) and pain interference (6.0) compared with those without neuropathic pain $(5.1, P=0.001$; pain interference, 5.2; $P=0.001)$. Sex was significantly associated with all 
Table 5 Gender differences across pain intensity, pain-related interference, anxiety, depression, quality of life and general health symptoms

\begin{tabular}{|c|c|c|c|c|}
\hline & Females, mean (SD) & Males, mean (SD) & $P$ value & Cohen's d \\
\hline Pain intensity & $5.57(1.8)$ & $4.74(1.7)$ & $<0.001$ & 0.48 \\
\hline Pain-related interference & $5.80(2.4)$ & $4.88(2.3)$ & $<0.001$ & 0.40 \\
\hline Anxiety (log) & $0.50(0.3)$ & $0.42(0.3)$ & $<0.001$ & 0.30 \\
\hline Depression (log) & $0.41(0.3)$ & $0.34(0.3)$ & 0.009 & 0.27 \\
\hline Quality of life & $60.09(20.5)$ & $67.64(19.4)$ & $<0.001$ & 0.38 \\
\hline General health symptoms & 3.17 (1.6) & $2.18(1.4)$ & $<0.001$ & 0.65 \\
\hline
\end{tabular}

*P value obtained in the linear mixed-models; anxiety and depression means are for the logged variable that was used in the linear mixedmodels.

outcomes of interest with females reporting worse outcomes than males did (Table 5).

Results of the linear mixed-models, which are summarized in eAppendix (available as Electronic Supplementary Material [ESM]), showed that after adjusting for age and sex, time was a significant predictor of pain intensity $(P<0.001)$, pain-related interference $(P<0.001)$, quality of life $(P<0.001)$, and general health symptoms $(P<0.001)$. This was the case irrespective of baseline cannabis status (naïve $v s$ already using; all interactions, $P>0.01)$ but also reasons for seeking medical cannabis $(P>0.01)$.

Sensitivity analyses (running the linear mixed-models by excluding the 12-month time-point) led to similar results in all models (in terms of significant predictors) except anxiety. In anxiety models, removing the last timepoint led to a significant main effect of time $(P<0.001)$ and seeking cannabis for pain $v s$ other reasons $(P=0.01)$.

\section{Discussion}

Patterns of cannabis consumption over time

Dried cannabis was the predominant product used at baseline; however, over time the combination of dried cannabis and cannabis oil became the most common forms of cannabis being consumed. Physicians have shifted to recommending and preferentially authorizing oil-based products. Over the course of the current study, patients who were predominantly using dried cannabis received cannabis oil and integrated oils into their regimen or switched to cannabis oil altogether. This change was echoed by Health Canada market data that also shows a significant shift to oil-based products from cannabis consumers. $^{30}$ Interestingly, following legalization of cannabis for recreational purposes in Canada in 2018, cannabis oil sales for non-medical (i.e., recreational) purposes has surpassed sales for medical purposes in
2019. ${ }^{31}$ What is needed as the cannabis industry moves forward, are several large-scale observational real-world evidence studies for which we know the inputs (i.e., what people are actually consuming from chemical composition standpoint-i.e., verified strains/ final products), which would then lead to meaningful randomized-controlled trials informed by the products being consumed in the real world. The favourable response to oil-based cannabis may be due to a slower onset of effect compared with smoked or vaporized cannabis, as well as easier dose titration and achieving a therapeutic effect with less adverse events (i.e., the feeling of being high). ${ }^{32}$ We suggest this may also reflect a desire for safer practice to ingest rather than be subjected to the harmful effects of smoking and the cost of purchasing a vaporizer. If the observational cohort was repeated today, it is conceivable that the majority of patients being authorized for medical cannabis would consume oil-based rather than inhaled products at the outset.

\section{Effectiveness of cannabis consumption}

In four of the six linear mixed-models, time was significant (i.e., the longer patients continued on medical cannabis, the greater the reported improvement of the symptom being investigated). Over time, individuals who continued consuming cannabis within this longitudinal study reported lower pain severity and pain interference scores, as well as improved quality of life and general health symptoms scores. It is worth noting that there was significant attrition in the analyses of these models and caution needs to be applied. Nevertheless, the results of the trajectory analyses are novel and have not been presented in the literature to date (see eAppendix, ESM). In previous studies, reductions in pain intensity were largest in one-day acute pain studies, and small and sometimes nonsignificant in studies of 12-week duration or longer, suggesting that the effectiveness of cannabinoids for CNCP may diminish over time. ${ }^{18}$ On the contrary, one 
controlled (open label) study has evaluated the safety and tolerability of cannabis used for one year in 215 patients. ${ }^{33}$ The authors of this study concluded that cannabis is tolerated well and relatively safe when used long-term. They suggest that the beneficial effects of cannabis appear to persist long-term and tolerance may not become a significant issue for patients on a stable regimen. Future studies are needed to determine whether tolerance becomes a significant issue for patients consuming cannabis long term.

Depression scores from the PHQ-4 initially improved and then worsened in our cohort. Data examining depression, stress, and anxiety were collected using a commercially available mobile application. It was found that cannabis users' ratings of anxiety and stress remained stable over time; however, depression scores significantly increased over time from baseline. ${ }^{34}$ This is consistent with recent evidence that using cannabis to cope with distress is associated with more cannabis-related problems and increased symptoms of depression. ${ }^{34}$

In the current cohort, the proportion of patients using opioids at each follow-up was decreased (40.8\% at baseline vs $23.9 \%$ at 12 months) suggesting an opioid-sparing effect with cannabis use. Interplay between opioid and cannabinoid receptors have been described as having overlapping neuroanatomical distribution of receptors, especially in the dorsal horn, locus ceruleus, and dorsal striatum. ${ }^{35}$ Co-activation of cannabinoid receptor type 1 and $\mathrm{mu} /$ kappa opioid receptors may also play a role in the exogenous opioid-sparing effect of medical cannabis. ${ }^{36}$ Preclinical studies have shown robust evidence for an opioid-sparing effect of cannabis, but these findings have not yet been replicated in human randomized clinical trials. Our data speaks to the need for robust clinical trials, given the overall increase in opioid cessation for those that remained on cannabis.

Sex differences among patients consuming cannabis

To date, the literature cites that men are more likely to use cannabis for recreational purposes, whereas the majority of women tend to use cannabis for medical purposes. ${ }^{37}$ In the current study, sex differences were seen with women having significantly higher pain severity, pain-related interference, anxiety, depression, quality of life, and general health symptoms outcomes (Table 5). Cuttler et al. reported that greater proportions of females use cannabis in smaller quantities and less frequently compared with males. ${ }^{37}$ Men were significantly more likely than women to report using joints, vaporizers, and concentrates, while women were significantly more likely than men to report using pipes and oral methods of administration. Women were significantly more likely than men to report using cannabis to treat anxiety, nausea, anorexia, irritable bowel syndrome, and headaches/migraines.

There may be biological and hormonal reasons that underlie differing sex responses to cannabis-derived compounds such as THC. ${ }^{38}$ In assessing sex differences for analgesics, Cooper and Craft reviewed animal and clinical studies. Six of seven studies using rat models assessing the effect of synthetic THC on a combination of tail pressure, paw pressure, complete Freund's adjuvant, mechanical allodynia, and heat hyperalgesia showed a significantly more potent response in female rodents. ${ }^{38} \mathrm{In}$ an experimental heat model, nabilone (a synthetic THC product) was given at doses of $0.5 \mathrm{mg}$ and $1.0 \mathrm{mg}$. Nabilone did not reduce pain intensity relative to placebo, but at the higher dose, hyperalgesia was reduced in women but not in men. ${ }^{39}$ In a double-blind, placebo-controlled study of healthy volunteers who smoke cannabis daily, the cold pressor test, a laboratory pain assay, was performed after participants smoked cannabis with THC $v s$ cannabis without THC. ${ }^{40}$ Smoked cannabis with THC showed a greater analgesic effect than cannabis without THC in men more than women. The variability of results associated with cannabis stems from the variability in the products tested. Current cannabis products are plant-derived with variable chemical compositions, so commercial products invariably carry these variations to the point of sale. Nabilone and plant-derived cannabis products vary significantly with respect to active ingredients. There are minimal data looking at differences in adverse effects with sex, and this would be an area for future research.

\section{Limitations}

We acknowledge that there are several limitations to the current work. Most medical cannabis literature to date lacks findings on optimal make-up, ratio of THC:CBD, and appropriate dosing of cannabis products. Our study did not close that major gap. Future designs must fill this void. Another limitation was our higher than anticipated attrition rate. Our study protocol called for 1,000 patients to be enrolled in the study. This goal was met, but a large number of enrolled patients did not complete their baseline survey, thereby leading to a smaller sample size (starting with only 757 patients). Patients were enrolled by counsellors and subsequently given a unique identifier to complete the survey either onsite or at their convenience from home. Over 243 patients were lost at this point, likely because there was no coordinator follow-up. Given the length of time taken to recruit the current cohort and turnover in the cannabis industry, three different study coordinators spanned the duration of the study, which likely affected the robustness of patient follow-ups. 
The number of participants who completed three-, six-, and 12-month follow-ups were 394 (52.0\%), 230 (30.4\%), and $104(13.7 \%)$, respectively. Given the attrition, the retention rate was $52 \%, 58 \%$, and $45 \%$ at three-, six-, and 12 months respectively relative to the previous time-point. This sequential retention rate combined to nearly $90 \%$ $(89.6 \%)$ attrition rate from baseline. A possible explanation for the attrition is that patients who tried cannabis and did not find it helpful for their symptoms subsequently withdrew from the study (i.e., stopped participating in the longitudinal questionnaires). There was no incentive (financial or otherwise) for patients to complete questionnaires as is typical for these types of longitudinal studies. Caution needs to be exercised when interpreting the linear mixed-model of time being a significant predictor of pain intensity, pain-related interference, quality of life, and general health symptoms. The positive effects of cannabis over time on the aforementioned domains may be in part due to selection bias. Patients who completed follow-up surveys tended to be patients still using cannabis because it was helpful to them. Unfortunately, it is difficult to ascertain the rationale for dropout. We did not capture adverse effects in our validated questionnaires or other survey questions. It is conceivable that adverse effects related to cannabis use played a role in the significant drop out of this observational cohort.

Finally, those who did not complete any follow-up were more likely to be unemployed or unable to work, have less than grade 12 education, higher levels of depressive symptoms, anxiety and common symptoms (based on ESAS), and lower quality of life than those who completed one or more follow-ups. This raises two significant questions regarding the use of cannabis for the domains studied herein. First, the above dropout might suggest that a higher severity of symptoms at baseline leads to an increased likelihood of dropout. These dropouts might be associated with a lack of effectiveness of cannabis in reducing severe symptoms. The other possibility is that cost is often a barrier to access cannabis. Patients who are more likely to be unemployed or have lower levels of education, would likely have more financial burden and thus seek cannabis from cheaper sources.

\section{Conclusions}

Two-hundred and seventeen (28\%) from an initial cohort of 757 patients who filled their assessment completed the six-month questionnaire and reported continuing the consumption of cannabis. Pain intensity scores and pain interference scores were significantly reduced and quality of life and general health symptoms were improved compared with baseline in the patients that continued using cannabis for six months. The attrition rate of patients was significant and the considerations for dropout are articulated above. Only one-third (230/757) of patients that trialed medical cannabis remained on the drug six months later. This clearly refutes the claim that cannabis is a panacea treatment for pain, and shows that cannabis may help a subset of patients. The positive signal from the trajectory analyses performed herein suggests that it is imperative that we begin to study the use of cannabinoid plant-based products with more rigorously designed studies. Nevertheless, we must first ensure that we understand the chemistry of products being consumed by patients in the real world and then utilize validated products in future randomized-controlled trials.

Author contributions Howard Meng, Hance Clarke, and Amol Deshpande contributed to the design of the study and writing of the manuscript. Gabrielle Page contributed to the data analysis and writing of the manuscript. Prabjit Ajrawat, Karim Ladha, Joseph Fiorellino, Alexander Huang, Yuvaraj Kotteeswaran, Alex McClarenBlades, and Lakshmi P. Kotra contributed to the writing of the manuscript. Bana Samman and Mary Dominicis contributed to the data analysis.

Acknowledgements We would like to acknowledge funding of this project provided by Canvas Rx. Canvas Rx provided funding for a research coordinator tasked with managing data collection. Canvas Rx did not have any role in data analysis or access to the manuscript before submission.

\section{Disclosures None.}

Funding statement Canvas Rx Clinics Canvas Rx was a private Cannabis Clinic operating the province of Ontario at the time of this study. They have since been acquired by Aurora Cannabis Inc. a Canadian licensed cannabis producer, Edmonton, Alberta, Canada. Canvas Rx provided funding for a research coordinator tasked with managing data collection. Canvas $\mathrm{Rx}$ did not have any role in data analysis or access to the manuscript before submission.

Editorial responsibility This submission was handled by Dr. Hilary P. Grocott, Editor-in-Chief, Canadian Journal of Anesthesia.

\section{References}

1. Schopflocher D, Taenzer P, Jovey $R$. The prevalence of chronic pain in Canada. Pain Res Manag 2011; 16: 445-50.

2. Lynch ME. The need for a Canadian pain strategy. Pain Res Manag 2011; 16: 77-80.

3. Aronoff GM. Chronic pain and the disability epidemic. Clin J Pain 1991; 7: 330-8.

4. Garcia Pereira F, Franca MH, Alochio de Paiva MC, Andrade LH, Viana MC. Prevalence and clinical profile of chronic pain and its association with mental disorders. Rev Saude Publica 2017; DOI: https://doi.org/10.11606/S1518-8787.2017051007025.

5. Manchikanti L, Fellows B, Ailinani H, Pampati V. Therapeutic use, abuse, and nonmedical use of opioids: a ten-year perspective. Pain Physician 2010; 13: 401-35. 
6. Patented Medicine Prices Review Board The market for prescription oral solid opioids, 2010 to 2017 - Canada and the United States. Chartbook National Prescription Drug Utilization Information System. Available from URL: http://www.pmprb-cepmb.gc.ca/ CMFiles/NPDUIS/chartbook_tramadol_e.pdf (accessed October 2020).

7. Ballantyne JC, LaForge KS. Opioid dependence and addiction during opioid treatment of chronic pain. Pain 2007; 129: 235-55.

8. Benyamin R, Trescot AM, Datta $S$, et al. Opioid complications and side effects. Pain Physician 2008; 11(2 Suppl): S105-20.

9. Busse JW, Craigie S, Juurlink DN, et al. Guideline for opioid therapy and chronic noncancer pain. CMAJ 2017; 189: E659-66.

10. Meng H, Dai T, Hanlon JG, Downar J, Alibhai SM, Clarke H. Cannabis and cannabinoids in cancer pain management. Curr Opin Support Palliat Care 2020; 14: 87-93.

11. Hazekamp A, Ware MA, Muller-Vahl KR, Abrams D, Grotenhermen $F$. The medicinal use of cannabis and cannabinoids-an international cross-sectional survey on administration forms. J Psychoactive Drugs 2013; 45: 199-210.

12. Troutt $W D$, DiDonato $M D$. Medical cannabis in Arizona: patient characteristics, perceptions, and impressions of medical cannabis legalization. J Psychoactive Drugs 2015; 47: 259-66.

13. Walsh Z, Callaway R, Belle-Isle L, et al. Cannabis for therapeutic purposes: patient characteristics, access, and reasons for use. Int $\mathbf{J}$ Drug Policy 2013; 24: 511-6.

14. Kelly S, Jhaveri MD, Sagar DR, Kendall DA, Chapman V. Activation of peripheral cannabinoid CB1 receptors inhibits mechanically evoked responses of spinal neurons in noninflamed rats and rats with hindpaw inflammation. Eur J Neurosci 2003; 18: 2239-43.

15. Ibrahim MM, Rude ML, Stagg NJ, et al. CB2 cannabinoid receptor mediation of antinociception. Pain 2006; 122: 36-42.

16. Aviram J, Samuelly-Leichtag G. Efficacy of cannabis-based medicines for pain management: a systematic review and metaanalysis of randomized controlled trials. Pain Physician 2017; 20: E755-96.

17. Meng H, Johnston B, Englesakis M, Moulin DE, Bhatia A. Selective cannabinoids for chronic neuropathic pain: a systematic review and meta-analysis. Anesth Analg 2017; 125: 1638-52.

18. Stockings E, Campbell G, Hall WD, et al. Cannabis and cannabinoids for the treatment of people with chronic noncancer pain conditions: a systematic review and metaanalysis of controlled and observational studies. Pain 2018; 159: 1932-54.

19. Hill KP. Medical marijuana for treatment of chronic pain and other medical and psychiatric problems: a clinical review. JAMA 2015; 313: 2474-83.

20. Kuhathasan N, Dufort A, MacKillop J, Gottschalk R, Minuzzi L, Frey BN. The use of cannabinoids for sleep: a critical review on clinical trials. Exp Clin Psychopharmacol 2019; 27: 383-401.

21. $\operatorname{Rod} K$. A pilot study of a medical cannabis - opioid reduction program. Am J Psychiatry Neurosci 2019; 7: 74-7.

22. Whiting PF, Wolff RF, Deshpande $S$, et al. Cannabinoids for medical use: a systematic review and meta-analysis. JAMA 2015; 313: 2456-73.

23. Gates PJ, Albertella L, Copeland J. The effects of cannabinoid administration on sleep: a systematic review of human studies. Sleep Med Rev 2014; 18: 477-87.

24. Lucas $P$. Rationale for cannabis-based interventions in the opioid overdose crisis. Harm Reduct J 2017; DOI: https://doi.org/10. 1186/s12954-017-0183-9
25. Tan G, Jensen MP, Thornby JI, Shanti BF. Validation of the brief pain inventory for chronic nonmalignant pain. J Pain 2004; 5: 133-7.

26. Turk DC, Fillingim RB, Ohrbach R, Patel KV. Assessment of psychosocial and functional impact of chronic pain. J Pain 2016; 17(9 Suppl): T21-49.

27. Agborsangaya $C B$, Lahtinen $M$, Cooke $T$, Johnson JA. Comparing the EQ-5D $3 \mathrm{~L}$ and 5L: measurement properties and association with chronic conditions and multimorbidity in the general population. Health Qual Life Outcomes 2014; DOI: https://doi.org/10.1186/1477-7525-12-74

28. David H, Bruera E. The Edmonton symptom assessment system 25 years later: past, present and future developments. J Pain Symptom Manage 2018; 53: 630-43.

29. Yawn BP, Wollan PC, Weingarten TN, Watson JC, Hooten WM, Melton LJ 3rd. The prevalence of neuropathic pain: clinical evaluation compared with screening tools in a community population. Pain Med 2009; 10: 586-93.

30. Government of Canada. Market data under the access to cannabis for medical purposes regulations - 2019. Available from URL: https://www.canada.ca/en/health-canada/services/drugsmedication/cannabis/research-data/medical-purpose.html (accessed October 2020).

31. Government of Canada. Cannabis extracts market data: Government of Canada; 2019. Available from URL: https:// www.canada.ca/en/health-canada/services/drugs-medication/ cannabis/research-data/market/extracts.html (accessed October 2020).

32. Barrus DG, Capogrossi KL, Cates SC, et al. Tasty THC: promises and challenges of cannabis edibles. Methods Rep RTI Press 2016; DOI: https://doi.org/10.3768/rtipress.2016.op.0035. 1611.

33. Ware MA, Wang T, Shapiro S, Collet JP; COMPASS Study Team. Cannabis for the Management of Pain: Assessment of Safety Study (COMPASS). J Pain 2015; 16: 1233-42.

34. Cuttler C, Spradlin A, McLaughlin RJ. A naturalistic examination of the perceived effects of cannabis on negative affect. J Affect Disord 2018; 235: 198-205.

35. Salio C, Fischer J, Franzoni MF, Mackie K, Kaneko T, Conrath $M$. CB1-cannabinoid and mu-opioid receptor co-localization on postsynaptic target in the rat dorsal horn. Neuroreport 2001; 12: 3689-92.

36. Rios C, Gomes I, Devi LA. mu opioid and CB1 cannabinoid receptor interactions: reciprocal inhibition of receptor signaling and neuritogenesis. Br J Pharmacol 2006; 148: 387-95.

37. Cuttler C, Mischley LK, Sexton M. Sex differences in cannabis use and effects: a cross-sectional survey of cannabis users. Cannabis Cannabinoid Res 2016; 1: 166-75.

38. Cooper ZD, Craft RM. Sex-dependent effects of cannabis and cannabinoids: a translational perspective. Neuropsychopharmacology 2018; 43: 34-51.

39. Redmond WJ, Goffaux P, Potvin S, Marchand S. Analgesic and antihyperalgesic effects of nabilone on experimental heat pain. Curr Med Res Opin 2008; 24: 1017-24.

40. Cooper ZD, Haney M. Sex-dependent effects of cannabis-induced analgesia. Drug Alcohol Depend 2016; 167: 112-20.

Publisher's Note Springer Nature remains neutral with regard to jurisdictional claims in published maps and institutional affiliations. 